\title{
Characteristics of respondents with glaucoma and dry eye in a national panel survey
}

This article was published in the following Dove Press journal:

Clinical Ophthalmology

12 November 2009

Number of times this article has been viewed

\section{Jordana K Schmier'}

David W Covert ${ }^{2}$

'Exponent Inc., Alexandria, VA, USA; ${ }^{2}$ Alcon Research, Ltd., Fort Worth, TX, USA
Correspondence: Jordana K Schmier I800 Diagonal Road, Suite 300,

Alexandria,VA 223I4, USA

Tel + I 57| 227 724 |

Fax + I 57| 2277299

Email jschmier@exponent.com
Background: There is an increasing body of evidence strongly suggesting that glaucoma medications may contribute to ocular surface disease and development of dry eye.

Objective: To identify glaucoma patients with dry eye, using a nationally representative sample, and to compare clinical and treatment characteristics with controls without dry eye.

Methods: Patients taking intraocular pressure-lowering medications were identified from the Medical Expenditure Panel Survey. A matched cohort without glaucoma served as controls. Dry eye was identified by diagnosis or use of prescription or over-the-counter medications. Demographic and clinical characteristics and medication use patterns were compared.

Results: The analysis identified 629 respondents with glaucoma and 6,934 controls without glaucoma. Dry eye was more common among glaucoma respondents than nonglaucoma controls $(16.5 \%$ vs $5.6 \%, P<0.0001)$. There was a nonsignificant trend for respondents with dry eye to report higher rates of glaucoma adjunctive therapy use compared to those without dry eye $(44.2 \%$ vs $35.0 \%, P<0.076)$. Prostaglandin analogs were the most common glaucoma medication.

Conclusions: This analysis found that the rate of dry eye was higher in patients with glaucoma than in controls. The use of glaucoma adjunctive therapies may increase the rate of dry eye in glaucoma patients.

Keywords: dry eye syndromes, health care surveys, glaucoma

\section{Introduction}

Glaucoma is typically characterized by increased intraocular pressure and progressive optic nerve damage. Treatment with intraocular pressure (IOP)-lowering agents can be successful at reducing intraocular pressure to target levels, although adjunctive therapy is often needed in order to do so. ${ }^{1-3}$ IOP-lowering agents may contribute to ocular surface disease (OSD), in part due to the preservatives used in medications. In particular, benzalkonium chloride (BAK), a preservative used in most IOP-lowering agents, has been shown in clinical and nonclinical settings to contribute to OSD, with greater difficulties associated with increased exposure to BAK through more medications or longer duration of use. ${ }^{4,5}$

Although little is known about the reasons for discontinuation or lack of adherence with glaucoma treatments, long-term adherence with glaucoma treatments is poor, with approximately half of glaucoma patients not continuing on medication past six months. ${ }^{6,7}$ Further, adherence rates may be associated with the type of medication, with higher adherence to prostaglandin analogs than beta-blockers. ${ }^{6}$ Adherence is affected by patient beliefs, disease characteristics, and satisfaction with treatment. ${ }^{8}$ 
One possible reason for discontinuation or inadequate adherence with glaucoma treatment is the development of OSD resulting in dry eye. ${ }^{4,5}$

The prevalence of dry eye, known as keratoconjunctivitis sicca, is highly variable in the literature. ${ }^{9}$ This may be driven somewhat by the wide range of practical definitions for dry eye, which cover symptom intensity and frequency, clinical characteristics, and impact. ${ }^{10}$ Multiple diagnostic tools exist and there is some, but not complete, overlap among them. ${ }^{11}$ The American Academy of Ophthalmology recognizes dry eye as a group of disorders of tear production or evaporation that lead to discomfort or impaired vision and that may damage the ocular surface. ${ }^{9}$ Risk factors for dry eye include age, vitamin or hormone intake or deficiencies, and medications, including IOP-lowering agents. ${ }^{9}$ Topical treatments for dry eye include cyclosporine, anti-inflammatory agents, mucolytic agents (available by prescription only) and over-the-counter lubricants or artificial tears. Treatment for dry eye is aimed not only at alleviating symptoms but also at preventing structural damage. Among patients with glaucoma, the prevalence of dry eye is higher than in the general population. ${ }^{12}$ However, few studies have explored the prevalence of concomitant dry eye and glaucoma in a general population.

The objective of this study was to use a nationallyrepresentative sample to identify patients with glaucoma with and without dry eye and to evaluate their clinical and treatment characteristics.

\section{Methods}

The Medical Expenditure Panel Survey (MEPS) is a national survey conducted under the auspices of the National Center for Health Statistics. Individuals, families, and medical providers are interviewed for the Household Component; the Insurance Component also includes interviews with employers. Each panel consists of five interviews over a twoyear period. Participants are selected from a representative sample of the participants in the previous year's National Health Interview Survey. Sampling weights are provided to project to the US population. Data collected include, but are not limited to personal characteristics, medical encounters and diagnoses, medication use, and insurance coverage. Providers and pharmacies provide verification of health care resource utilization while use of over-the-counter medications is self-reported.

For this analysis, three panels, covering the calendar years 2003-2006, were examined. Participants with glaucoma were identified by the use of a glaucoma medication
(MEPS medication code 164 'topical glaucoma agents'). A healthy, or nonglaucoma, comparator group was identified by including respondents whose ages were in the interquartile range (ie, from the 25 th to 75 th percentile) of the glaucoma patients. In each cohort, those with concomitant dry eye were identified by a diagnosis code (International Statistical Classification of Diseases and Related Health Problems [ICD-9] code 375) or the use of a prescription or over-the-counter dry eye medication. Dry eye medications were initially identified by medication code (MEPS medication code 168 'ophthalmic lubricants and irritations') with the list of medications also manually examined. Procedures that could be indicative of either condition, such as trabeculoplasty or punctal occlusion, were not specifically reviewed and used as tools for identifying patients with glaucoma or dry eye; the focus of the study was on medication use and its impact rather than a diagnosis of the condition of interest.

Participants were characterized in terms of demographic characteristics (age, gender, race, insurance, health status), ophthalmic comorbidities (identified by ICD-9 diagnosis codes 360-379 and present in 1\% or more of respondents with glaucoma), and nonophthalmic chronic conditions of interest. For participants with glaucoma, glaucoma medications were described by type (adrenergics, beta blockers, carbonic anhydrase inhibitors, miotics, prostaglandin analogs, and fixed combinations). The use of monotherapy vs adjunctive therapies was also compared, with the use of adjunctive therapy defined as the listing of two or more glaucoma medications at one or more interviews during the follow-up period. Among the cohorts with glaucoma and matched controls initially identified, a secondary analysis was conducted, comparing patients who had dry eye with those who did not. Their characteristics were examined based on the presence of glaucoma. MEPS sampling weights were used throughout the analysis. The analysis was conducted using SAS software (v. 9.2; SAS Institute, Cary, NC), with chi-squared tests for categorical variables and analysis of variance used for continuous variables.

\section{Results}

Across the three panels, a total of 629 respondents were identified with glaucoma and the nonglaucoma control group included 6,934 respondents. In the cohort with glaucoma, $16.5 \%$ had evidence of dry eye compared to $5.6 \%$ in the nonglaucoma controls $(P<0.0001)$.

Demographic characteristics of glaucoma and nonglaucoma control cohorts are presented in Table 1. Gender and age are reflective of the known epidemiology of glaucoma. 
Table I Patients with glaucoma vs controls: Demographic characteristics

\begin{tabular}{|c|c|c|c|c|c|c|}
\hline \multirow[t]{2}{*}{ Characteristic } & \multicolumn{2}{|l|}{ Glaucoma patients } & \multicolumn{2}{|l|}{ Controls } & \multicolumn{2}{|l|}{ Total } \\
\hline & Without dry eye & With dry eye & Without dry eye & With dry eye & Without dry eye & With dry eye \\
\hline \multirow[t]{2}{*}{$\mathrm{N}$ (Respondents) } & 525 & 104 & 6,548 & 386 & 7,073 & 490 \\
\hline & Mean & Mean & Mean & Mean* & Mean & Mean* \\
\hline \multirow[t]{2}{*}{ Age (years) } & 66.7 & 68.2 & 65.1 & 67.3 & 65.2 & 67.5 \\
\hline & Frequency & Frequency & Frequency & Frequency* & Frequency & Frequency* \\
\hline Sex, \% female & $58.7 \%$ & $58.8 \%$ & $52.6 \%$ & $61.8 \%$ & $53.1 \%$ & $61.6 \%$ \\
\hline \multicolumn{7}{|l|}{ Race } \\
\hline White & $81.5 \%$ & $72.7 \%$ & $85.1 \%$ & $86.2 \%$ & $84.8 \%$ & $85.2 \%$ \\
\hline Black & $14.3 \%$ & $22.1 \%$ & $9.6 \%$ & $8.2 \%$ & $9.9 \%$ & $9.3 \%$ \\
\hline Asian & $2.2 \%$ & $2.2 \%$ & $3.3 \%$ & $3.6 \%$ & $3.2 \%$ & $3.5 \%$ \\
\hline Multiple races & $1.6 \%$ & $1.0 \%$ & $1.2 \%$ & $1.2 \%$ & $1.2 \%$ & $1.2 \%$ \\
\hline Other & $0.4 \%$ & $1.9 \%$ & $0.9 \%$ & $0.8 \%$ & $0.9 \%$ & $0.9 \%$ \\
\hline
\end{tabular}

Notes: *Indicates significant differences $(P<0.05)$ : Glaucoma cohort: none. Controls with and without dry eye: age and gender. Total with and without dry eye: age and gender.

Also, a higher percentage of females than males in both the glaucoma and nonglaucoma cohorts experienced dry eye requiring prescription or over-the-counter medications for symptom relief. Table 2 provides detail on clinical characteristics. In all groups, a majority of respondents stated that they were in 'very good' or 'good' health. Patients with dry eye experienced more visual impairment in both the glaucoma and control groups. The most common ophthalmic comorbidity was cataract, with macular degeneration also not uncommon. As expected, the rate of disorders of the lacrimal system was much higher in patients with dry eye and it was not reported at all in patients who were not using medications for dry eye. The most common nonophthalmic chronic conditions were hypertension, hypercholesterolemia and diabetes in both the glaucoma and nonglaucoma groups. Patients with dry eye had significantly higher rates of hypertension and diabetes.

Medication use is presented in Table 3. Respondents could report taking more than one medication; as a result the sum of the frequency of medications exceeds $100 \%$. Prostaglandin analogs were the most often reported glaucoma medication ( $65 \%$ of all glaucoma respondents and $53 \%$ of respondents with glaucoma and dry eye). Just over one-third (36.6\%) of patients reported two or more glaucoma medications at any interview during the panel. There was a trend for glaucoma patients with dry eye to report higher rates of adjunctive therapy use compared to glaucoma patients without dry eye ( $44.2 \%$ vs $35.0 \%, P<0.076)$.

Patients with dry eye were also compared by the presence of glaucoma. There were a total of 490 dry eye patients, 104 of whom had glaucoma compared to 525 of 7,073 patients without dry eye reporting glaucoma $(21.2 \%$ vs $7.4 \%$, $P<0.0001)$. Demographic characteristics for glaucoma and nonglaucoma groups were similar; however, a larger percentage of black patients used glaucoma medications in all cohorts. For example, among patients with dry eye and glaucoma, $22.1 \%$ were black, while among dry eye patients without glaucoma, only $8.2 \%$ were black.

\section{Discussion}

This analysis suggests that one in six patients with glaucoma have dry eye symptoms severe enough that they seek some form of treatment. The rate of dry eye among age-matched controls not using IOP-lowering medications was only about one-third (5.6\%) of the rate for patients with glaucoma (16.5\%). Similarly, patients with dry eye were also being treated for glaucoma significantly more often than those without dry eye. Finally, there was a nonsignificant trend for higher rates of dry eye among glaucoma patients reporting adjunctive therapy use.

A review of the epidemiology of dry eye found published prevalence ranging from $6 \%$ to $34 \% \cdot{ }^{13}$ In a general population aged 43-84 years, one study found that $13 \%$ reported dry eye symptoms over a five-year period, with higher prevalence associated with age and among patients with diabetes or allergies. ${ }^{14}$ Another large study of the general population found that the prevalence of dry eye symptoms among men ranged from $4 \%-8 \%$, and was associated with age and the presence of hypertension and benign prostatic hyperplasia. ${ }^{15}$ Among women, the rate was found to be slightly higher in the general population and there were differences by educational status and geography, with an age-adjusted prevalence 
Table 2 Patients with glaucoma vs controls: Clinical characteristics

\begin{tabular}{|c|c|c|c|c|c|c|}
\hline \multirow[t]{2}{*}{ Characteristic (n) } & \multicolumn{2}{|l|}{ Glaucoma patients } & \multicolumn{2}{|l|}{ Controls } & \multicolumn{2}{|l|}{ Total } \\
\hline & Without dry eye & With dry eye & Without dry eye & With dry eye & Without dry eye & $\begin{array}{l}\text { With dry } \\
\text { eye }\end{array}$ \\
\hline \multicolumn{7}{|l|}{ Health status } \\
\hline Excellent & $2.0 \%$ & $3.3 \%$ & $5.8 \%$ & $2.9 \%$ & $5.5 \%$ & $3.0 \%$ \\
\hline Very good & $21.2 \%$ & $15.9 \%$ & $25.0 \%$ & $20.8 \%$ & $24.7 \%$ & $20.4 \%$ \\
\hline Good & $37.3 \%$ & $44.0 \%$ & $38.0 \%$ & $36.0 \%$ & $37.9 \%$ & $36.6 \%$ \\
\hline Fair & $28.0 \%$ & $22.5 \%$ & $20.9 \%$ & $26.3 \%$ & $21.4 \%$ & $26.0 \%$ \\
\hline Poor & $8.4 \%$ & $14.2 \%$ & $6.7 \%$ & $11.8 \%$ & $6.8 \%$ & $12.0 \%$ \\
\hline Other (don't know, not applicable) & $3.1 \%$ & $0.1 \%$ & $3.6 \%$ & $2.3 \%$ & $3.6 \%$ & $2.1 \%$ \\
\hline \multicolumn{7}{|l|}{ Vision impairment } \\
\hline No impairment & $72.5 \%$ & $67.3 \% *$ & $85.8 \%$ & $73.3 \% *$ & $84.8 \%$ & $72.9 \% *$ \\
\hline Some difficulty & $16.7 \%$ & $20.2 \%$ & $9.5 \%$ & $19.2 \%$ & $10.0 \%$ & $19.3 \%$ \\
\hline Impaired near but not far & $7.5 \%$ & $5.9 \%$ & $2.3 \%$ & $5.5 \%$ & $2.7 \%$ & $5.5 \%$ \\
\hline Impaired both near and far & $1.6 \%$ & $2.7 \%$ & $0.3 \%$ & $1.1 \%$ & $0.4 \%$ & $1.2 \%$ \\
\hline Blind & $1.3 \%$ & $4.0 \%$ & $0.8 \%$ & $0.9 \%$ & $0.9 \%$ & $1.1 \%$ \\
\hline $\begin{array}{l}\text { Difficulty seeing with contacts/glasses, } \\
\% \text { yes }\end{array}$ & $11.9 \%$ & $13.1 \%$ & $3.5 \%$ & $8.6 \% *$ & $4.1 \%$ & $8.9 \% *$ \\
\hline \multicolumn{7}{|l|}{$\begin{array}{l}\text { Presence of eye conditions } \\
\text { (ICD-9 code) }\end{array}$} \\
\hline Disorders of the globe $(360)$ & $1.2 \%$ & $7.2 \%$ & $1.4 \%$ & $10.5 \% *$ & $1.4 \%$ & $10.3 \% *$ \\
\hline Other retinal disorders (362) & $5.9 \%$ & $8.1 \%$ & $2.0 \%$ & $3.8 \%$ & $2.2 \%$ & $4.2 \% *$ \\
\hline Cataract (366) & $13.8 \%$ & $39.5 \%$ & $6.5 \%$ & $45.5 \% *$ & $7.0 \%$ & $45.1 \% *$ \\
\hline $\begin{array}{l}\text { Disorders of refraction/accommodation } \\
\text { (367) }\end{array}$ & $2.0 \%$ & $2.0 \%$ & $3.4 \%$ & $1.6 \% *$ & $3.3 \%$ & $1.6 \% *$ \\
\hline Visual disturbances (368) & $1.2 \%$ & $2.1 \%$ & $1.3 \%$ & $5.5 \%$ & $1.3 \%$ & $5.2 \% *$ \\
\hline Blindness and low vision (369) & $1.3 \%$ & $0.8 \%$ & $0.7 \%$ & $1.4 \%$ & $0.8 \%$ & $1.3 \%$ \\
\hline Inflammation of eyelids (373) & $0.3 \%$ & $1.5 \%$ & $0.3 \%$ & $0.8 \%$ & $0.3 \%$ & $0.8 \%$ \\
\hline Disorders of lacrimal system (375) & $0.0 \%$ & $15.8 \%$ & $0.0 \%$ & $20.7 \%$ & $0.0 \%$ & $20.5 \%$ \\
\hline Disorders of optic nerve (377) & $0.4 \%$ & $1.1 \%$ & $0.1 \%$ & $0.2 \%$ & $0.1 \%$ & $0.3 \%$ \\
\hline Other disorders of eye (379) & $5.0 \%$ & $10.6 \%$ & $2.5 \%$ & $10.4 \% *$ & $2.7 \%$ & $10.4 \% *$ \\
\hline \multicolumn{7}{|l|}{ Presence of other chronic conditions } \\
\hline Hypertension (40I) & $47.9 \%$ & $58.0 \%$ & $47.2 \%$ & $54.3 \% *$ & $47.3 \%$ & $54.6 \% *$ \\
\hline Hypercholesterolemia (272) & $26.6 \%$ & $34.4 \%$ & $33.6 \%$ & $36.9 \%$ & $33.0 \%$ & $36.7 \%$ \\
\hline Diabetes (250) & $20.3 \%$ & $27.7 \%$ & $17.0 \%$ & $25.0 \% *$ & $17.3 \%$ & $25.2 \% *$ \\
\hline
\end{tabular}

Notes: *Indicates significant differences $(P<0.05)$ : Glaucoma cohort: cataract. Controls with and without dry eye: vision impairment, difficulty seeing with contacts/glasses, disorders of the globe, cataract, disorders of refraction/accommodation, other disorders of the eye, hypertension, and diabetes. Total with and without dry eye: vision impairment, difficulty seeing with contacts/glasses, disorders of the globe, other retinal disorders, cataract, disorders of refraction/accommodation, visual disturbances, other disorders of the eye, hypertension, and diabetes.

Abbreviation: ICD-9, International Statistical Classification of Diseases and Related Health Problems.

of $7.8 \% .^{16}$ Among the glaucoma patients in our study, $16.2 \%$ of men and $16.8 \%$ of women had concomitant dry eye, which we deemed not remarkable enough for detailed analysis, though it may suggest that the addition of BAK is an equilibrating factor that eliminates the difference between the sexes. In the much larger control group, though, women had a significantly higher rate of dry eye symptoms requiring therapy. A clinical study that identified OSD using the Ocular
Surface Disease Index (OSDI) found that more than half of glaucoma patients have at least one symptom, and that the use of antiglaucoma agents containing BAK increases the risk of OSD. ${ }^{5}$ A recent study found that the use of multiple IOPlowering agents is associated with a significantly increased rate of moderate and severe dry eye. ${ }^{17}$

The rate of concomitant dry eye in this study among glaucoma patients, $16.5 \%$, is consistent with existing 
Table 3 Medication use

\begin{tabular}{|c|c|c|}
\hline \multirow[t]{3}{*}{ Medication } & \multicolumn{2}{|c|}{ Glaucoma patients } \\
\hline & \multirow{2}{*}{$\frac{\text { Without dry eye }}{\text { Frequency^ }^{\wedge}}$} & \multirow{2}{*}{$\frac{\text { With dry eye }}{\text { Frequency^ }^{\wedge}}$} \\
\hline & & \\
\hline \multicolumn{3}{|l|}{ IOP-lowering agents } \\
\hline Prostaglandin analogs & $64.9 \%$ & $53.4 \%$ \\
\hline Beta blockers & $36.9 \%$ & $50.7 \%$ \\
\hline Adrenergics & $20.8 \%$ & $28.5 \%$ \\
\hline Combination products & $16.7 \%$ & $19.4 \%$ \\
\hline $\begin{array}{l}\text { Carbonic anhydrase } \\
\text { inhibitors }\end{array}$ & $11.0 \%$ & $14.8 \%$ \\
\hline Miotics & $2.0 \%$ & $2.5 \%$ \\
\hline
\end{tabular}

Notes: ${ }^{\wedge}$ Total exceeds $100 \%$ as patients could report more than one agent. Abbreviation: IOP, intraocular pressure.

literature, given that the identification methods required a respondent be sufficiently symptomatic to seek treatment. There is no definitive diagnostic tool for dry eye. ${ }^{13}$ The OSDI may identify subclinical dry eye cases, thus resulting in a higher rate compared to that reported here. Alternatively, a study that identifies dry eye only by prescription medication and/or an ICD-9 diagnosis might underreport cases of dry eye compared to this analysis. Either might lead to different outcomes. For example, limiting an analysis to prescription medication only would likely capture only the most severe cases while using a comprehensive tool such as the OSDI might label patients as having dry eye even though they had never been sufficiently bothered to seek treatment. A database with clinical information as well as over-the-counter and prescription data would be required in order to evaluate the impact of different case finding methods more fully.

The design of this survey made it difficult to ascertain if respondents with glaucoma had pre-existing dry eye that was exacerbated by topical IOP-lowering therapy or if it developed after the start of treatment with IOP-lowering agents. Also, there may have been other factors contributing to dry eye but they could not be fully explored. While there was a list of all medications taken by respondents with glaucoma, it was not considered feasible to review the list for evidence of medications that may be associated with dry eye. For example, as oral beta blockers used to treat hypertension can also contribute to dry eye disease, it is possible that hypertension treatment could exacerbate any propensity towards dry eye from antiglaucoma agents. It would have been interesting to know about type of glaucoma and other ophthalmic conditions, but the MEPS data include only a three-digit ICD-9 code.
We considered identifying patients by glaucoma diagnosis rather than only by medication use. However that would have presented a challenge, with two very different types of patients included using that definition. First, it was possible that a single diagnosis could have been recorded as part of an evaluation to rule out disease. These patients would have had no exposure to glaucoma medications. In contrast, it is also possible that we could have identified patients with previous surgical interventions whose glaucoma was monitored but controlled without medications. Unless the intervention occurred during the time of observation, there would be no way to distinguish these patients. Patients who did not require medication, either because they did not have glaucoma or they were successfully treated with a surgical intervention, were not the target group for this analysis. Thus, patients identified by diagnosis with no evidence of IOP-lowering medication were not included in the glaucoma cohort.

In examining the use of adjunctive therapies, we explored alternate definitions. Only 33 of the glaucoma patients reported two or more antiglaucoma medications at all five of the survey interviews, so that definition was deemed too restrictive. In fact, 350 of the 629 glaucoma patients only mentioned one antiglaucoma medication during the entire study period. Other studies have found the rate of adjunctive therapy over one year to be less than $30 \%$, at least among users of prostaglandin analogs, ${ }^{18,19}$ so this was not considered unusual. Given the low frequency of prescriptions for adjunctive therapy even among those who did report one or more, we wonder whether limiting our analysis to patients who reported multiple prescriptions would have demonstrated a greater differential in dry eye rates compared those with no prescriptions. With so few respondents reporting multiple adjunctive therapies, though, the analysis would not have had sufficient power to detect a significant difference. Also, we were unable to separate out adjunctive therapies containing BAK that might be more likely to cause dry eye from those that do not. At the time of data collection, only one beta blocker formulation and one prostaglandin analog were available without BAK. However, as the MEPS prescription data did not consistently provide brand names, it was not possible to make this distinction. Our findings indicated a nonsignificant statistical trend for higher rates of dry eye among patients reporting use of adjunctive therapies. Had the population size been $6 \%$ larger with similar rates of dry eye, the difference would have been significant; an updated analysis using another panel of MEPS data might find that the trend reaches significance. 
The MEPS data are unequaled in terms of scope and validity. The survey excludes the military and the institutionalized populations but is otherwise nationally representative. Diagnoses and resource use are confirmed with health care providers and prescription data are validated at pharmacies. The inclusion of self-reported over-the-counter medications, although not validated, is a valuable addition compared with other databases. Self-report can be limited by recall bias, which raises analytic challenges, ${ }^{20}$ though little is known about report of over-the-counter medications and the extent of recall bias.

The objective of this analysis was to explore the relationship between glaucoma, dry eye, and the use of antiglaucoma medications. While further analysis and large epidemiologic studies will be useful, these findings demonstrate that glaucoma and/or the use of IOP-lowering medications are associated with the presence of dry eye. Analysis of additional panels of MEPS data or other databases that include over-the-counter medications would be helpful to confirm these findings.

\section{Disclosures}

The authors report no conflicts of interest in this work.

\section{References}

1. Costagliola C, Del Prete A, Verolino M, et al. Effect of $0.005 \%$ latanoprost once daily on intraocular pressure in glaucomatous patients not adequately controlled by beta-blockers twice daily: a 3-year follow-up. Experience and incidence of side effects in a prospective study on 76 patients. Graefes Arch Clin Exp Ophthalmol. 2002;240(5): 379-386.

2. Netland PA, Landry T, Sullivan EK, et al. Travoprost compared with latanoprost and timolol in patients with open-angle glaucoma or ocular hypertension. Am J Ophthalmol. 2001;132(4):472-484.

3. Sit AJ, Weinreb RN, Crowston JG, Kripke DF, Liu JH. Sustained effect of travoprost on diurnal and nocturnal intraocular pressure. Am J Ophthalmol. 2006;141(6):1131-1133.

4. Baudouin C. Detrimental effect of preservatives in eyedrops: implications for the treatment of glaucoma. Acta Ophthalmol. 2008; 86(7):716-726.
5. Leung EW, Medeiros FA, Weinreb RN. Prevalence of ocular surface disease in glaucoma patients. J Glaucoma. 2008;17(5):350-355.

6. Nordstrom BL, Friedman DS, Mozaffari E, Quigley HA, Walker AM. Persistence and adherence with topical glaucoma therapy. Am $J$ Ophthalmol. 2005;140(4):598-606.

7. Friedman DS, Quigley HA, Gelb L, et al. Using pharmacy claims data to study adherence to glaucoma medications: methodology and findings of the Glaucoma Adherence and Persistency Study (GAPS). Invest Ophthalmol Vis Sci. 2007;48(11):5052-5057.

8. Friedman DS, Hahn SR, Gelb L, et al. Doctor-patient communication, health-related beliefs, and adherence in glaucoma results from the Glaucoma Adherence and Persistency Study. Ophthalmology. 2008;115(8):1320-1327, 1327.e1-3.

9. American Academy of Ophthalmology. Preferred Practice Pattern: Dry Eye Syndrome. San Francisco, CA: American Academy of Ophthalmology; 2008.

10. Perry HD. Dry eye disease: pathophysiology, classification, and diagnosis. Am J Manag Care. 2008;14(Suppl 3):S79-S87.

11. Moore JE, Graham JE, Goodall EA, et al. Concordance between common dry eye diagnostic tests. Br J Ophthalmol. 2009;93(1): $66-72$.

12. Ali FS, Akpek EK. Glaucoma and dry eye. Ophthalmology. 2009; 116(6): 1232.

13. The epidemiology of dry eye disease: report of the Epidemiology Subcommittee of the International Dry Eye WorkShop (2007). Ocul Surf. 2007;5(2):93-107.

14. Moss SE, Klein R, Klein BE. Long-term incidence of dry eye in an older population. Optom Vis Sci. 2008;85(8):668-674.

15. Schaumberg DA, Dana R, Buring JE, Sullivan DA. Prevalence of dry eye disease among US men: estimates from the Physicians' Health Studies. Arch Ophthalmol. 2009;127(6):763-768.

16. Schaumberg DA, Sullivan DA, Buring JE, Dana MR. Prevalence of dry eye syndrome among US women. Am J Ophthalmol. 2003;136(2):318-326.

17. Rossi GC, Tinelli C, Pasinetti GM, Milano G, Bianchi PE. Dry eye syndrome-related quality of life in glaucoma patients. Eur J Ophthalmol. 2009;19(4):572-579.

18. Schmier JK, Covert DW, Robin AL. First-year treatment patterns among new initiators of topical prostaglandin analogs. Curr Med Res Opin. 2009;25(4):851-858.

19. Schmier JK, Covert DW, Robin AL. Estimated first-year costs of prostaglandin analogs with/without adjunctive therapy for glaucoma management: a United States perspective. Curr Med Res Opin. 2007;23(11):2867-2875.

20. Schmier JK, Halpern MT. Patient recall and recall bias of health state and health status. Exp Rev Pharmacoecon Outcomes Res. 2004;4(2):89-93.
Clinical Ophthalmology

\section{Publish your work in this journal}

Clinical Ophthalmology is an international, peer-reviewed journal covering all subspecialties within ophthalmology. Key topics include: Optometry; Visual science; Pharmacology and drug therapy in eye diseases; Basic Sciences; Primary and Secondary eye care; Patient Safety and Quality of Care Improvements. This journal is indexed on Submit your manuscript here: http://www.dovepress.com/clinical-ophthalmology-journal

\section{Dovepress}

PubMed Central and CAS, and is the official journal of The Society of Clinical Ophthalmology (SCO). The manuscript management system is completely online and includes a very quick and fair peer-review system, which is all easy to use. Visit http://www.dovepress.com/ testimonials.php to read real quotes from published authors. 